\title{
Experiências metodológicas de ensino no Pibid Filosofia da Universidade Federal do Ceará
}

\author{
Evanildo Costeski20 \\ José Carlos Silva de Almeida ${ }^{21}$
}

\begin{abstract}
Resumo: O presente relato apresenta duas experiências metodológicas de ensino de filosofia desenvolvidas no âmbito do subprojeto PIBID Filosofia da Universidade Federal do Ceará, nas quais os conteúdos filosóficos ministrados valorizam a vivência do discente como ponto de partida para a reflexão e ao qual se busca, ao fim do processo, transformar a sua realidade cotidiana.
\end{abstract}

Palavras-chave: ensino; filosofia; metodologias; cotidiano.

\section{Experiencias metodológicas de enseñanza en PIBID Filosofía de la Universidad Federal de Ceará}

Resumen: El presente informe presenta dos experiencias metodológicas de enseñanza de filosofía desarrolladas en el ámbito del sub-proyecto Programa Institucional de Beca de Iniciación a la Docencia - Filosofía (PIBID) de la Universidad Federal del Ceará, en las cuales los contenidos filosóficos trabajados valoran la experiencia del alumno como punto de partida para la reflexión y en los cuales se busca, al final del proceso, cambiar su realidad cotidiana.

Palabras clave: enseñanza; filosofía; metodologías; cotidiano.

\section{Introdução}

O projeto Pibid Filosofia da Universidade Federal do Ceará teve início em 2008 com o primeiro edital nacional do Pibid. Na oportunidade, as licenciaturas priorizadas pela Capes foram Matemática, Química, Biologia e

20 Mestre e Doutor em Filosofia pela Pontifícia Universidade Gregoriana (Roma), com estágio de pós-doutorado no Centro de História de Cultura da Universidade Nova de Lisboa. Atuou como professor de Filosofia no Ensino fundamental e Médio de 1993 a 1995. Desde 2005 é Professor do Curso de Filosofia da Universidade Federal do Ceará. É coordenador de área do subprojeto Filosofia PIBID UFC. E-mail: evanildoc@uol.com.br 21 Bacharel, Licenciado e Mestre em Filosofia pela Pontifícia Universidade Católica do Rio de Janeiro (PUC/RJ). Doutor em Filosofia pela Pontifícia Universidade Antonianum (PUA) em Roma. Atuou como Professor do Ensino Fundamental e Médio nas áreas de Filosofia e Ensino Religioso, no período de 1989 a 1997, no Rio de Janeiro. Desde 2007 é Professor do Curso de Filosofia da Universidade Federal do Ceará (UFC). É coordenador de área do subprojeto Filosofia Pibid UFC. E-mail: jcdafilosofia@hotmail.com

Revista Digital de Ensino de Filosofia - Santa Maria - vol.2., n.2 - jul./dez. 2016. 
Física, consideradas as áreas mais carentes de professores no nível médio de ensino. Não obstante a priorização de certas licenciaturas, o curso de Filosofia da UFC conseguiu participar do projeto institucional pelo fato de apresentar uma proposta voltada à interdisciplinaridade. Essa característica está sendo mantida em todos os trabalhos executados até o momento presente, em cumprimento do que reza a Portaria Capes n 96, de 18 de julho de 2013 em vários trechos de sua redação:

Inserir os licenciandos no cotidiano de escolas da rede pública de educação, proporcionando-lhes oportunidades de criação e participação em experiências metodológicas, tecnológicas e práticas docentes de caráter inovador e interdisciplinar que busquem a superação de problemas identificados no processo de ensinoaprendizagem [grifo nosso]. ${ }^{22}$

Desenvolvimento de ações que valorizem o trabalho coletivo, interdisciplinar e com intencionalidade pedagógica clara para 0 processo de ensino-aprendizagem [grifo nosso]. ${ }^{23}$

Com efeito, se é verdade que o ensino constitui um desafio constante para todas as áreas, é um fato que a aprendizagem dos conteúdos das ciências consideradas mais "duras" - Matemática, Física e áreas afins -, sofre com o crescente desinteresse dos alunos das escolas públicas, principalmente daquelas existentes nas periferias das grandes cidades, como é o caso de Fortaleza. O nosso projeto visava justamente buscar reverter essa situação, estando dessa forma em perfeita consonância com que afirma a Portaria $n^{\circ} 96$ da Capes sobre o Pibid:

O Pibid é um programa da Coordenação de
Aperfeiçoamento de Pessoal de Nível Superior
(Capes) que tem por finalidade fomentar a
iniciação à docência, contribuindo para o
aperfeiçoamento da formação de docentes em
nível superior e para a melhoria da qualidade da
educação básica pública brasileira [grifo nosso]. ${ }^{24}$

O nosso ponto de partida para a mudança do cenário fora a própria situação

22 Capítulo I - Disposições Gerais - Seção II - Dos Objetivos - Inciso IV do Artigo 4º p. 2.

${ }^{23}$ Capítulo II - Do Projeto - Seção I - Das Características do Projeto e Subprojetos - Inciso Il do Artigo 6०, p. 3.

${ }^{24}$ Capítulo I - Disposições Gerais - Seção I - Da Definição - Artigo 2º , p. 2.

Revista Digital de Ensino de Filosofia - Santa Maria - vol.2., n.2 - jul./dez. 2016. 
do aluno de ensino médio. Pelo fato de sofrer constantemente pressões subjetivas e objetivas, tanto psico-afetivas quanto sócio-econômicas, o aluno das escolas públicas do ensino médio encontra-se normalmente em uma situação de vulnerabilidade, distante de um aprendizado satisfatório. Somamse a isso as preocupações técnicas do mundo do trabalho, que passam igualmente a fazer parte da vida do jovem estudante. Diante desse quadro de precariedade, o ensino de filosofia, se quiser apresentar algum resultado concreto, deve propor algumas possíveis soluções. A princípio, a reflexão filosófica possibilita aos alunos compreenderem melhor a sua realidade imediata, ajudando-os a conquistar sua autonomia afetiva e social, necessárias para um melhor aprendizado em ciências, sejam elas as humanas, as sociais, as naturais ou as exatas. No que diz respeito especificamente às ciências naturais e exatas, cabe à filosofia esclarecer igualmente as fundamentações epistemológicas e éticas das atividades científicas, pois se é verdade que a racionalização científica é autônoma, é verdade também que não pode prescindir do discurso ético e moral. A atividade científica deve ter um sentido para os jovens estudantes. Ora, a filosofia pode perfeitamente esclarecer esse sentido. Essa era a preocupação principal do Pibid Filosofia da UFC no momento de sua implantação, a saber, propiciar aos estudantes do ensino médio e aos licenciandos do curso de Filosofia os meios adequados para poderem articular ciência e vida, teoria e prática, aproximando, assim, os conteúdos filosóficos à vida dos jovens e das ciências em geral.

Paralelo a essa atividade interdisciplinar, o Pibid Filosofia aspirou desde o início a garantir uma maior autonomia para o ensino de filosofia nas escolas, pelo fato de a filosofia finalmente ter se tornado uma disciplina obrigatória no ensino médio, com o Parecer do Conselho Nacional de Educação n 38/2006 homologado em 14/08/2006 - e o Projeto de Lei 11.684, de 02 de junho de 2008, que altera o parágrafo 36 da Lei de Diretrizes e Base da Educação Nacional. Durante muitos anos, o ensino de filosofia ficou ausente da maioria das escolas brasileiras. Isso fez com que os cursos universitários de graduação em filosofia se distanciassem do ensino médio e passassem a se preocupar mais com a pesquisa filosófica do que com o seu ensino, acentuando a formação de bacharéis. Essa situação felizmente está mudando. Mas muito precisa ainda ser feito, principalmente em relação às metodologias de ensino Revista Digital de Ensino de Filosofia - Santa Maria - vol.2., n.2 - jul./dez. 2016. 
de filosofia. 25 O Pibid Filosofia da UFC assumiu, em seu projeto inicial e mantém até hoje, essa incumbência. $\bigcirc$ ensino de filosofia deve ser histórico, temático ou histórico-temático? O professor deve "ensinar filosofia" ou "ensinar a filosofar"? São questões que não podem ser negligenciadas. O que se constatou é que o ensino de filosofia não pode se restringir apenas ao aprendizado histórico dos conteúdos filosóficos. Embora fundamentais, os conteúdos filosóficos deverão ser contextualizados para que os jovens possam pensar, em sala de aula e em grupos de estudos, a sua situação vivida.

Nota-se, com isso, que as formações humanísticas e científicas não podem ser separadas. A filosofia oferece todas as condições para se pensar uma educação interdisciplinar, onde valores morais e éticos possam coexistir com pesquisas científicas, sem prejuízos para $\circ$ meio-ambiente e 0 desenvolvimento da civilização humana. A esse respeito a Portaria da Capes sobre $O$ Pibid afirma que $O$ projeto deve contemplar "questões socioambientais, éticas e a diversidade como princípio de equidade social, que devem perpassar transversalmente todos os subprojetos". 26 Deve-se apenas ressaltar que essa função não é específica da filosofia. Todas as ciências devem visar à formação integral dos jovens.

\section{A Metodologia do Professor Silvio Gallo}

Para se alcançar esse objetivo, o projeto Pibid Filosofia buscou inspiração, em um primeiro momento, na metodologia proposta pelo Professor Silvio Gallo, da Unicamp. A filosofia deve trabalhar com dois conteúdos: um sistemático e coerente, oriundo dos textos e dos filósofos que constituem a História da Filosofia; e outro mais assistemático e incoerente, originário da própria vivência dos alunos. Mas qual seria a metodologia mais adequada?

Para Sílvio Gallo, "ensinar filosofia é ensinar o ato, o processo do

25 A Portaria $n^{\circ} 96$ da Capes sobre o Pibid faz alusão a essa questão quando afirma que se deve "inserir os licenciandos no cotidiano de escolas da rede pública de educação, proporcionando-lhes oportunidades de criação e participação em experiências metodológicas, tecnológicas e práticas docentes de caráter inovador e interdisciplinar que busquem a superação de problemas identificados no processo de ensino-aprendizagem" [grifo nosso]. Cf. nota 1.

${ }^{26}$ Capítulo II - Do Projeto - Seção I - Das Características do Projeto e Subprojetos - Inciso $\checkmark$ do Artigo $7^{\circ}$, p. 4.

Revista Digital de Ensino de Filosofia - Santa Maria - vol.2., n.2 - jul./dez. 2016. 
filosofar" (2007, p. 16). Para tanto, ele desenvolve quatro momentos: Sensibilização, Problematização, Investigação e Criação de Conceitos (GALLO, 2007, p. 25-31). A nossa proposta também envolve quatro etapas, com algumas adaptações. A primeira é chamada de Problematização inicial. Nesta fase, o pensamento filosófico é apresentado ao estudante do ensino médio não de forma dogmática, mas a partir de um estado de crise, ou seja, de uma tomada de consciência dos problemas da vida humana, da sociedade e do mundo em geral. Assim como a etapa da Sensibilização de Sílvio Gallo, o objetivo deste momento é fazer com os estudantes vivam e "sintam na pele" um problema filosófico a partir de um elemento não-filosófico (GALLO, 2007, p. 26). Para essa problematização inicial, são utilizados recursos diversos, tais como: filmes, documentários, letras de músicas, programas de televisão, trechos de obras literárias, etc., em suma, algo que desperte a atenção dos alunos.

Após o levantamento de temas e problemas gerais vividos pelos estudantes, os alunos bolsistas do Pibid Filosofia, junto com o professor supervisor, são convidados a fazer uma primeira classificação dos mesmos. Evidentemente, não se trata ainda de uma classificação filosófica, mas apenas metodológica. Passa-se então para a segunda etapa, denominada Investigação dos problemas. Esta pode ser feita de duas maneiras: uma mais temática e outra mais histórica. A temática se concentra sobre os problemas levantados pelos alunos e classificados preliminarmente pelo professor supervisor e pelos bolsistas. Com base nessa classificação, os bolsistas selecionam textos filosóficos apropriados à problemática levantada. Por exemplo: para problemas éticos e morais, podem ser selecionados textos de filósofos clássicos (Platão, Aristóteles e Epicuro) e de modernos e contemporâneos (Descartes, Kant e Levinas), por exemplo; para questões existenciais, destacam-se as contribuições de Kierkegaard, Camus e Sartre; enquanto para problemas sociais e econômicos, textos de Karl Marx e assim por diante. Após a leitura de trechos selecionados das obras de autores clássicos e contemporâneos, os alunos bolsistas tratam de discutir com os estudantes, buscando a contextualização dos textos filosóficos. Nesse momento, busca-se esclarecer dúvidas sobre o pensamento do filósofo, da sua vida e da sua relação com a história humana em geral. Nesse processo Revista Digital de Ensino de Filosofia - Santa Maria - vol.2., n.2 - jul./dez. 2016. 
prioritariamente temático, a história da filosofia não será ainda o centro da investigação, mas "um recurso necessário para pensar o nosso próprio tempo, nossos próprios problemas" (GALLO, 2007, p. 26). Com o tempo, depois de várias leituras de textos filosóficos do período clássico, moderno e contemporâneo, o aluno poderá alcançar uma visão mais ampla e geral da história da filosofia. Bem entendido: o objetivo primeiro da investigação temática será a reflexão sobre as questões atuais, não o conhecimento aprofundado da história da filosofia.

Já na investigação histórica, por sua vez, os problemas atuais continuam a ser o foco principal, mas, ao contrário do processo temático, a reflexão sobre eles será indireta, a partir da própria interpretação da história da filosofia. Para isso, o estudo da história da filosofia deverá ser contextualizado, de acordo com as questões levantadas pelos alunos e classificadas previamente. Por exemplo: depois da apresentação de alguns mitos, os bolsistas poderão trabalhar com alguns diálogos platônicos, como A República, a Apologia de Sócrates e O Banquete. Através do Mito da Caverna, narrativa que abre o sétimo livro de A República de Platão, poderse-á falar da alienação midiática contemporânea; já a Apologia destaca, entre outros problemas, o da violência, o da aplicação da lei e da justiça, e O Banquete das diversas formas de amor, que constituem, certamente, um discurso sempre atraente aos jovens.

No período moderno, a leitura das duas primeiras meditações de Descartes pode levar o jovem a questionar o seu conhecimento sobre a realidade. Será que estou sonhando? O que estou vendo passar diante dos meus olhos será um homem ou um robô? São questões que podem ir ao encontro de várias indagações destacadas pelos jovens na primeira etapa. Os famosos quatro ídolos de Bacon, que bloqueiam a mente humana: ĺdolos da Tribo, Ídolos da Caverna, Ídolos do Foro e ídolos do Teatro, ajudam outrossim a mostrar para o aluno que a nossa mente pode estar impregnada de conceitos falsos e ideológicos; enquanto a leitura de partes do Manifesto Comunista de Karl Marx revela ao jovem as situações injustas presentes no trabalho, na economia e na sociedade atual.

Enfim, na investigação histórica, cabem aos bolsistas selecionarem textos e interpretá-los de forma contextualizada, respeitando o próprio Revista Digital de Ensino de Filosofia - Santa Maria - vol.2., n.2 - jul./dez. 2016. 
desenvolvimento do pensamento filosófico. O resultado é semelhante ao da investigação temática, já que ambos os processos têm como foco principal os problemas classificados na primeira fase. A diferença é apenas metodológica. $\mathrm{Na}$ investigação temática, os textos são selecionados a partir dos temas previamente classificados, enquanto na histórica os textos são lidos e estudados de forma sistemática, respeitando o percurso histórico; apenas no final são contextualizados de acordo com os temas selecionados.

Para o professor Sílvio Gallo, a Criação de Conceitos é a última etapa do processo de ensino. Sugerimos que esta seja uma terceira etapa, seguida de uma quarta, chamada de Socialização de Conceitos. Isso porque a criação constitui um processo puramente individual que precisa, certamente, ser socializado com os demais alunos em sala de aula. Para definir o ensino de filosofia como criação de conceitos, Sílvio Gallo cita os filósofos franceses Deleuze e Guattari:

O filósofo é o amigo do conceito, ele é o conceito em potência. Quer dizer que a filosofia não é uma simples arte de formar, de inventar ou de fabricar conceitos, pois os conceitos não são necessariamente formas, achados ou produtos. A filosofia, mais rigorosamente, é a disciplina que consiste em criar conceitos (...) Criar conceitos sempre novos é o objeto da filosofia. É porque o conceito precisa ser criado que ele remete ao filósofo como aquele que o tem em potência, ou que tem sua potência e sua competência (...) Os conceitos não nos esperam inteiramente feitos, como corpos celestes. Não há céu para os conceitos. Eles devem ser inventados, fabricados ou antes criados, e não seriam nada sem a assinatura daqueles que os criam (...) Que valeria um filósofo do qual se pudesse dizer: ele não criou um conceito, ele não criou seus conceitos? (DELEUZE; GUATTARI, 2007, p. 13-14; GALLO, 2007, p. 23).

Bem entendido: não se trata aqui de um "conceito científico", abstrato, mas de "uma forma racional de equacionar um problema ou problemas, exprimindo uma visão coerente do vivido; isto é, o conceito é uma forma de lançar inteligibilidade sobre o mundo" (GALLO, 2007, p. 23). O estudante será motivado a criar conceitos em sala de aula, com base na leitura de textos 
filosóficos e discussões com o professor e demais alunos. Os conceitos não precisam ser definitivos nem precisam explicar todos os problemas. Esses podem ser fundamentados não apenas na filosofia, mas também nas ciências em geral. $O$ jovem estudante do ensino médio poderá criar inicialmente apenas um conceito pessoal, para explicar sua própria experiência e, assim, orientar filosoficamente a sua vida. Isso não obscurece o fato de ele ter feito, de forma autônoma, uma experiência de pensamento. Nesse momento, é importante que 0 professor deixe 0 estudante a vontade, para que 0 pensamento possa fluir livremente, orientando-o apenas quando necessário.

Por fim, apresentamos a última etapa, chamada por nós de Socialização dos conceitos: após a criação individual de conceitos filosóficos iniciais, os estudantes do ensino médio são encorajados a partilhá-los com os outros colegas da sala. Nesse momento, os conceitos poderão ser criticados, possibilitando, assim, um amadurecimento do aprendizado filosófico. O importante é que o aluno aprenda a discutir e a compartilhar sua experiência reflexiva. A socialização de saberes é fundamental para o ensino médio. Da mesma forma que outros conhecimentos, os conceitos filosóficos precisam ser compartilhados. A socialização pode ser feita tanto em sala de aula, como em semanas específicas, destinadas a trabalhos científicos e culturais na Escola. Essa experiência é importante porque faz com que a filosofia se integre mais no currículo escolar e nas atividades interdisciplinares, necessárias para o crescimento intelectual do aluno.

Como já foi dito, os conceitos não são meros instrumentos científicos, mas verdadeiras armas que podem servir para transformar a vida do aluno e o meio em que vive. Eis como conclui Sílvio Gallo (2007, p. 31):

\footnotetext{
Os conceitos são ferramentas, e podem ser armas, dependendo do uso que deles fazemos. É claro que as armas não são boas ou más em si mesmas; os conceitos podem ser armas de transformação ou armas de conservação, dependendo das intenções de quem os usa. A aula de filosofia como oficina de conceitos está longe, portanto, de ser um empreendimento ingênuo ou alienado. Pode ser arma de luta; o conceito pode ser ferramenta de engajamento.
} 
Mas uma arma ou ferramenta de transformação pode ser institucionalizada oficialmente? Como conciliar a criação de conceitos filosóficos com o currículo escolar? Como a filosofia pode ser revolucionária dentro da instituição escolar brasileira? É suficiente afirmar que a filosofia é necessária para a formação da cidadania e da democracia para torná-la revolucionária? São questões que precisam ser devidamente esclarecidas, para que a filosofia possa cumprir o seu papel na educação dos jovens. Para isso, é necessário que a filosofia extrapole os limites da sala de aula e passe a atuar na escola e na comunidade como um todo.

Com efeito, a socialização dos conceitos não pode ser feita apenas em sala de aula, mas também na comunidade em que se encontra a escola. A escola não é apenas um espaço para o ensino formal. Ela representa um ponto de apoio acadêmico, cultural e esportivo para muitas comunidades. As salas de aula continuam a ser o foco principal, mas existem muitas outras atividades na escola e na comunidade que exigem atenção dos alunos, como as preparações específicas para o Enem, para as Olimpíadas de Conhecimento etc. A filosofia não pode ficar alheia a essas atividades. Além dessas atividades prioritariamente acadêmicas, pode-se pensar em atividades interdisciplinares e debates culturais sobre cinema e filosofia, literatura e filosofia e assim por diante, não apenas para os alunos da escola, mas para os pais dos alunos e toda a comunidade próxima à escola. ${ }^{27}$

Essa foi, em linhas gerais, a proposta inicial do Pibid Filosofia da UFC. Nem tudo foi aplicado como se previa inicialmente. As atividades escolares têm uma dinâmica própria que extrapolam muitas vezes as intenções iniciais. Mas o espírito geral do projeto foi cumprido, a saber, inserir, de forma interdisciplinar, as questões filosóficas na vida dos estudantes, a partir de problemas levantados pelos mesmos. Isso se deu na prática mediante dois grandes projetos, realizados no ano de 2010 em duas escolas de Fortaleza, com resultados bastante significativos: "Pensando naquilo", sobre a questão

27 A Portaria $n^{\circ} 96$ da Capes sobre o Pibid postula que o projeto institucional deve abranger diversas características e dimensões da iniciação à docência, sendo uma delas a de "elaboração de ações no espaço escolar a partir do diálogo e da articulação dos membros do programa, e destes com a comunidade". Cf. Inciso IX do Artigo $6^{\circ}$ - Capítulo II - Do Projeto - Seção I - Das Características do Projeto e Subprojetos, p. 3.

Revista Digital de Ensino de Filosofia - Santa Maria - vol.2., n.2 - jul./dez. 2016. 
da sexualidade na adolescência, realizado no Liceu de Messejana e o projeto sobre "Alimentação", no Liceu do Conjunto Ceará.

\section{A Teoria do Cotidiano de Agnes Heller}

A partir de 2012, houve uma significativa ampliação nas atividades do Pibid Filosofia da UFC. O trabalho que até então se desenvolvera em duas escolas apenas, a saber, o Liceu de Messejana e o Liceu do Conjunto Ceará, com um contingente de cinco alunos e um professor supervisor por escola, é estendido para uma terceira instituição de ensino médio, a saber, o Colégio Estadual Justiniano de Serpa, localizado no centro de Fortaleza, conhecida como uma das escolas públicas cearense de regime integral. ${ }^{28}$ Vale salientar aqui que a ideia de integralidade levada adiante no Colégio Justiniano de Serpa pauta-se fundamentalmente numa duplicação do tempo disponibilizado para as diversas áreas do conhecimento quando se compara com as demais escolas de ensino médio do Estado do Ceará. Soma-se uma hora/aula a já tão exígua hora/aula semanal ofertada ao ensino de filosofia. Com uma grade de horário semanal centrada em sala de aula, pouco espaço fica destinado para as ações dos bolsistas do subprojeto Filosofia do Pibid nos horários entre turnos, enquanto a figura do contra turno é inexistente. Por sua vez as ações interdisciplinares tornam-se restritas aos momentos ou semanas culturais do colégio.

Mas, face a tal cenário, em que o trabalho fica mais situado na sala de aula, deve-se destacar o emprego de um outro referencial teórico no que diz respeito à metodologia de ensino de filosofia. A professora supervisora adota a Teoria do Cotidiano de Agnes Heller, autora de obras como O Cotidiano e a História (1972), Sociologia de la vita cotidiana (1991) e Para mudar a vida (1982), e as suas possibilidades de emprego na área educacional, observando que a dimensão de cotidiano é por diversas vezes uma dimensão menosprezada pela própria filosofia e pelas ciências sociais.

28 Nesse sentido cumprimos a recomendação da Capes na Portaria $n^{\circ} 96$ que trata sobre o Pibid quando afirma que as ações do projeto devem ser desenvolvidas também em escolas de regime de tempo integral. Cf. Inciso II do Artigo $8^{\circ}$ - Capítulo II Do Projeto - Seção I - Das Características do Projeto e Subprojetos, p. 4. 
A prática metodológica dinamizada com o emprego da Teoria do Cotidiano de Agnes Heller abre-se para a percepção de que a reflexão filosófica, a partir do não cotidiano, é necessária para um aprofundamento histórico-crítico mediante uma diversidade de perspectivas, quer seja dentro da esfera do cotidiano, quer seja no âmbito do não cotidiano. Caso contrário, o cotidiano gera um dinamismo limitado, um círculo vicioso, que impossibilita o seu aprofundamento e, conseqüentemente, sua superação.

O cotidiano é uma realidade inegável e vivenciada por todos, mas nem todos percebem o não cotidiano. Perceber os dois numa perspectiva filosófica tem colaborado para o exercício da aprendizagem, mas exige, por parte do professor, a aproximação ao dia-a-dia do aluno e o conhecimento das diversas manifestações de linguagem e de expressões simbólicas que formam o seu cotidiano: a moda, a musicalidade, seus gestos, suas relações com os ídolos, etc. Nesta perspectiva, os elementos de analogia utilizados durante o processo de ensino-aprendizagem são pertencentes, direta e/ou indiretamente, à realidade dos alunos. Há uma visão ingênua que considera que a Teoria do Cotidiano não acolhe a necessidade de aprofundamento teórico, o que não corresponde, pois com o uso da cotidianidade como elemento colaborador da aprendizagem, ocorre a associação do conceito filosófico ao dinamismo da sociedade.

Com isso, os alunos devem ser estimulados ao exercício da superação dos limites impostos pelos pensamentos preconcebidos (preconceitos). A construção do conhecimento se dá a partir da iniciativa dos próprios alunos, por isso o professor adota uma postura de mediador entre os alunos e os conhecimentos filosóficos. Em busca de uma renovação na prática pedagógica é possivel observar professores de filosofia que focam suas aulas em temas cotidianos e montam dinâmicas de grupo, sem que estabeleçam relações entre os temas em debate e os conceitos filosóficos. Em assim ocorrendo, distanciam-se da vivência da Teoria do Cotidiano, pois o exercício reflexivo será limitado, marcado pelo uso freqüente e sem propósitos filosóficos de dinâmicas abusivas. A própria escolha dos temas que servirão de base para os debates ocupa, por si só, um lugar teórico metodológico na Teoria do Cotidiano. A sua escolha não pode ficar, tão somente, a cargo dos alunos. Ocorrendo isso, os professores poderão ficar emersos pela imposição de temas Revista Digital de Ensino de Filosofia - Santa Maria - vol.2., n.2 - jul./dez. 2016. 
predominantes, disseminados pelos interesses midiáticos, terminando por fortalecer o processo de alienação. As escolhas das temáticas têm que apresentar vínculo com o pensar filosófico. Os temas devem contribuir para desvelar realidades, tais quais, elucidar a grande pergunta antropológica da Filosofia: "O que é o Homem?", para ajudar a desvelar o funcionamento da sociedade baseada na produção de mercadorias e tentar compreender o sentido da vida.

O processo educacional requer, portanto, o cuidado em não se cair no mecanicismo; para isso, Agnes Heller nos remete à necessidade de superarmos a formação para a mera individualidade em favor de uma educação que conduza $\circ$ aluno a perceber sua condição de singularidade e de particularidade. Esse é o pressuposto para que o aluno se eleve de sua condição individual para uma visão de pertencimento à coletividade, à comunidade, ao gênero humano.

\section{Conclusão}

Em 2014, com o novo edital da Capes para o Pibid, o subprojeto Filosofia da Universidade Federal do Ceará passou por uma nova ampliação. Atualmente o nosso subprojeto atua em 04 escolas públicas do ensino médio em Fortaleza, envolvendo 02 coordenadores de área, 04 professores supervisores e 28 bolsistas de iniciação à docência. Dos egressos, vários já são docentes em escolas públicas e privadas do Estado do Ceará e participam do Programa de Pós-graduação em Filosofia da UFC. Vale acrescentar ainda, por último, que 02 ex-alunos do Pibid Filosofia são atualmente professores supervisores.

Quando novamente se discute se a filosofia deve permanecer como disciplina ou apenas como conteúdo transversal no Ensino Médio, salientamos que nossa experiência com o PIBID Filosofia prova que o ensino "disciplinar" é realmente essencial. Parece de fato contraditório enquadrar o conteúdo filosófico em uma "disciplina". Não seria mais coerente com a liberdade filosófica a transversalidade, em vez de um conteúdo disciplinar, sujeito ao controle de presença, às avaliações e reprovações próprias das disciplinas? É certo que o conteúdo filosófico não se limita ao ensino curricular, entretanto, Revista Digital de Ensino de Filosofia - Santa Maria - vol.2., n.2 - jul./dez. 2016. 
não podemos esquecer daquilo que é óbvio: não existe de fato interdisciplinaridade sem disciplinas curriculares. Sem a obrigatoriedade da filosofia no Ensino Médio, o conteúdo filosófico seria aos poucos relativizado e terminaria fatalmente se perdendo em meios a tantas outras preocupações tidas como mais técnicas e urgentes.

\section{Referências}

CAPES. Portaria $n^{\circ}$ 96, de 18 de julho de 2013. Aperfeiçoa e atualiza as normas do Programa Institucional de Bolsa de Iniciação à Docência. Disponível em

<https://www.capes.gov.br/images/stories/download/legislacao/Portaria_096_ 18jul13_AprovaRegulamentoPIBID.pdf>. Acesso em: 31 mar. 2015.

COSTESKI, Evanildo. Considerações sobre o Ensino de Filosofia no Nível Médio. In: SOUZA, Vinícios R.; FICK, Vera M. S. (Org.). Epistemologia e Tecnologias para o Ensino das Ciëncias Humanas e Sociais. Fortaleza: Tiprogresso, 2009, v. 03, p. 12-26.

DELEUZE, Gilles; GUATTARI, Félix. O que é a Filosofia? Rio de Janeiro: Editora 34, 2007. SILVEIRA,

GALLO, Sílvio. A filosofia e seu ensino: conceito e transversalidade. In:

René J. T.; GOTO, Roberto. Filosofia no Ensino Médio: Temas problemas e propostas. São Paulo: Loyola, 2007, p. 15-36.

HELLER, Agnes. O Cotidiano e a história. Rio de Janeiro: Paz e Terra, 1972.

HELLER, Agnes. Sociologia de la vida cotidiana. Prefácio de Gyorgy Lukacs. Barcelona: Peninsula, 1991.

HELLER, Agnes. Para mudar de vida: felicidade, liberdade e democracia. Entrevista a Ferdinando Adornato. São Paulo: Brasiliense, 1982. 